\title{
¿QUÉ ERA EL “BARRIO INGLÉS”? \\ ARQUEOLOGÍA DE UN CONJUNTO DE VIVIENDAS DEL FERROCARRIL Central Argentino, Rosario, Argentina
}

\author{
Gustavo Fernetti*
}

\begin{abstract}
Resumen
Construido en la zona industrial de Rosario (Santa Fe, Argentina) a fines del siglo XIX y anexo a las instalaciones del Ferrocarril Central Argentino (FCCA), lo que hoy llamamos "Barrio Inglés" tuvo otros nombres: Barrio Talleres, Morrison Building, Batten Cottages. Este trabajo intenta obtener una "ontología operativa" de este conjunto residencial, analizando el registro hallado arqueológico, junto con las condiciones sociales que le dieron origen y en las que vivieron los constructores y primeros pobladores. Esas condiciones aún hoy permanecen olvidadas. Este estudio inicial permitirá una aproximación al tema, para así habilitar futuras investigaciones de mayor aproximación.
\end{abstract}

Palabras clave: barrios, inmigración, arqueología urbana, basureros

\begin{abstract}
Built in the industrial zone of Rosario (Santa Fe, Argentina) in the late nineteenth century and annex to the facilities of the Ferrocarril Central Argentino (FCCA), what is now called "Barrio Inglés" ("British Quarter") formerly had other names: Barrio Talleres, Morrison Building, and Batten Cottages. This paper attempts to get an "operational onthology" of the quarter, analyzing -into an archaeological framethe relicts found and the social conditions that allowed the making of the neighbourhood, and where both builders and inhabitants had lived. Those conditions today remain still forgotten. The present paper about them, will open further and more detailed studies about this subject of investigation.
\end{abstract}

Keywords: quarter, immigration, urban archeology, landfills

\section{Introducción}

Durante la introducción del capitalismo en Argentina (1856 a 1880) se impulsó el trazado ferroviario como factor de transporte de personas, mercancías importadas y salida de bienes agrarios, dentro de un modelo económico agroexportador. El consecuente avance ferroviario a través del territorio nacional no se redujo al simple tendido de vías, sino a la constitución de un sistema en constante expan-

\footnotetext{
* Centro de Estudios de Arqueología Histórica, Universidad Nacional de Rosario. Museo Itinerante del Barrio de la Refinería. Programa de Preservación y Rehabilitación del Patrimonio - Municipalidad de Rosario. Junta de Historia de Rosario. arqfernetti@ hotmail.com
} 
sión, con instalaciones de alta complejidad en permanente búsqueda de la eficiencia y rentabilidad, con sus propias normas, códigos y lenguajes, propios de las empresas inglesas que invirtieron en el ferrocarril. A partir de 1870, la empresa Central Argentine Railways transformó profundamente Rosario, adquiriendo suelo constantemente. (Martínez de San Vicente 1998; Rigotti y Pampinella 2008) Si bien el ferrocarril aparecía para el usuario como servicio, era una industria con tecnología particular y rentabilidad creciente. Frente a este panorama, mientras la carencia de mano de obra campesina en el país se resolvió mediante una inmigración poco calificada, el tendido ferroviario y su funcionamiento requería trabajadores experimentados en solucionar problemas inéditos en el país. Por ello a partir de 1870 arribó personal seleccionado para el trabajo industrial-ferroviario, su administración e inspección. (Denault, L. y J. Landis 1999). Estos inmigrantes generaron sus propios barrios en las ciudades argentinas, con sociabilidad, arquitectura, habitación y convivencia: los denominados barrios ingleses o ferroviarios. Dado que los ferrocarriles -como empresa- tuvieron una demanda de trabajadores del riel (originalmente "navvies", navegantes) apareció la necesidad de su radicación inmediata a las estaciones y talleres (Findlay 1891). Así, en Rosario ${ }^{1}$ se construyó para estos inmigrantes un conjunto de viviendas, denominado popularmente "Barrio Inglés".

\section{El llamado "Barrio Inglés"}

El hoy llamado "Barrio Inglés" se ubicaba en la zona norte de Rosario, a $500 \mathrm{~m}$ de la vía Rosario-Córdoba, sobre Av. Alberdi, estaba formado por dos tipos de vivienda y una iglesia con una escuela incorporada a ese edificio (Figura 1). El nombre "Barrio Inglés" es reciente; en los documentos se mencionan a Batten Cottage y Morrison Building o a veces "Talleres Nuevos" y "Talleres F.C.R." Otros toponímicos eran "Barrio Talleres", "Parada Castellanos", "Barrio de los Ingleses" "ferroviario", "de los ferroviarios" y "Barrio Jardín". En Conocer y Cuidar la Ciudad en que Vivimos (Cicutti 1997) se mencionan como "Viviendas (para) trabajadores del Ferrocarril Central Argentino"

La historia del conjunto edilicio es bastante oscura en el sentido de fechas de diseño y edificación.

Este barrio posee escasa bibliografía que lo describa y las perspectivas disponibles son de tipo patrimonialista, arquitectónico o turístico, que arrojan poca luz sobre el grupo que habitó este barrio. Por ello -y a los fines de aportar a la historia social de la ciudad- nuestro objetivo es intentar una "definición operativa" de este conjunto residencial, para el grupo histórico que lo habitó en la época de su diseño y edificación (1880-1910) a fin de poder más adelante realizar trabajkos de mayor aproximación al tema.

Los planos urbanos más antiguos del sector (Araya 1895 y Thedy 1899) muestran un ramal de maniobras que deriva a los Talleres del FCCA, pasando por el frente del Morrison Building. Según Lanciotti el Morrison Building fue construido por el FCCA a instancias del principal accionista, Walter Morrison presidente del FCCA de 1887 a 1909 y de allí el nombre del conjunto (Lanciotti 2007, 
Damus 2013). En las guías de arquitectura, se suele atribuir el conjunto al arquitecto ferroviario Eustace Conder, pero sin aportar documentación probatoria.
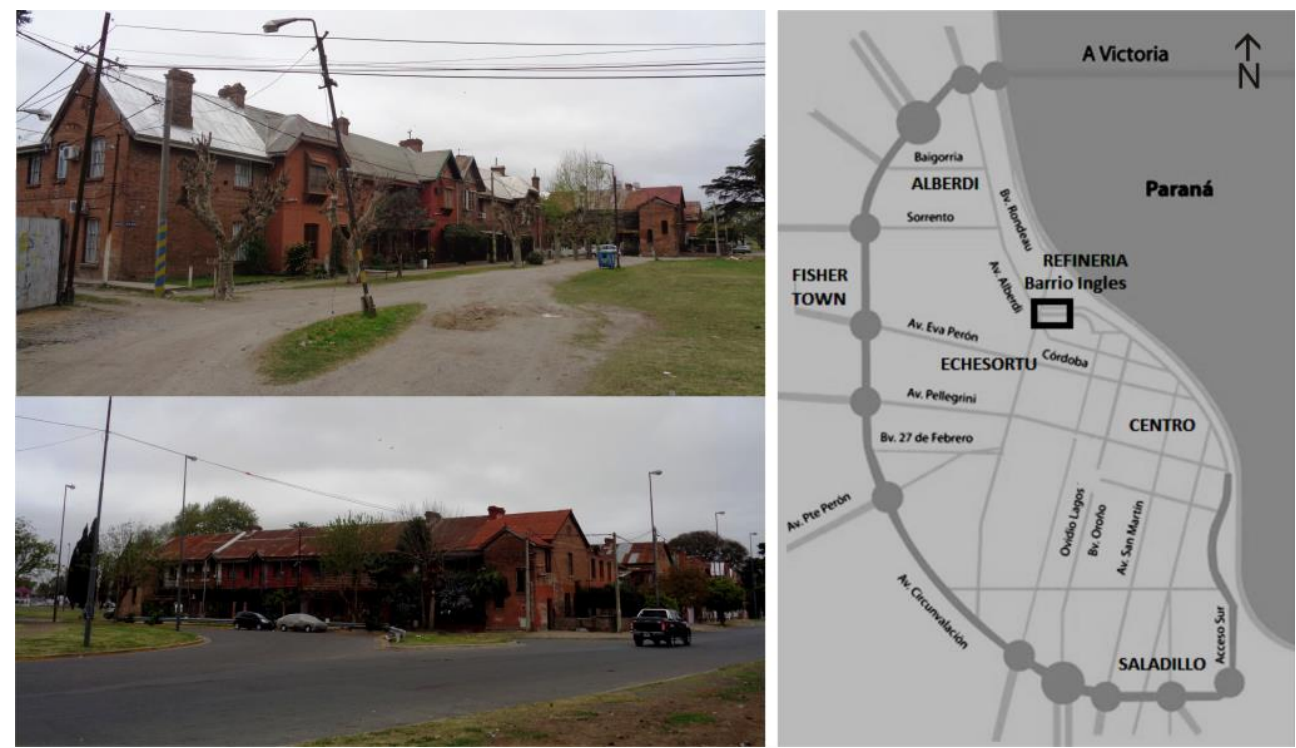

Figura 1: Ubicación y vista hacia el noreste del "Barrio Inglés" (Foto del autor)

El origen del término Batten Cottage es dudoso, pudo referir tanto a la casa rural (cottage) tradicional "de listones" (batten) o bien a John Winterbotham Batten (1836-1891), accionista del FCCA del FCC a Ensenada y director del Stafford \& Uttoxeter Railway (Damus 2013, Lanciotti, comunicación personal 2014).

Aunque no pueda adjudicárselo directamente al Barrio Inglés, el registro arqueológico de más antiguo hallado (Sitio MO3 a $75 \mathrm{~m}$ del conjunto edilicio) es un fragmento de botella de cerveza rosarina marca Magdelín de cronología precisa 1874-78, en un contexto inmediato de cuatro fragmentos de azulejos Pais de Calais (c. 1870-1880). Los demás fragmentos hallados en contexto se encuadran, cronológicamente, entre 1890 y 1920. Los documentos consultados (fotografías, postales) establecen cronologías entre 1888 y 1890. Podemos suponer entonces la fecha de edificación entre 1889 y 1890 , ya que documentos anteriores (planos municipales de 1870,1880 y 1882) no evidencian en el predio más que tierra rural sin edificación y los posteriores a 1890 ya representan gráficamente al barrio.

Los documentos administrativos, sin embargo, no dieron cuenta de las personas y grupos que allí residieron y, sobre todo, de su modo de vida.

La composición por nacionalidades de la población es heterogénea, a pesar del nombre adjudicado al barrio. El Censo Nacional de $1895^{2}$ ubica en el "Barrio Inglés" -Sección 14- a varios obreros y empleados ferroviarios. Los de nacionalidad británica (ingleses, escoceses, irlandeses) tienen oficios varios: maquinista (Thomas Varey, Mc Carthy), soldador (William Barckley) mecánico (Steven Murphy y O. Mc Nally, irlandeses), foguista (Jerome Ferguson) señaleros (Herder Jutting y Alfred Gilbert, ingleses), fitter (reparador, James Jones), maquinista 
(Glaad, galés), pintor (Colin Bain Calder, escocés), empleados (C. Browlking, Mr. Smith) y un escribano (Miguel Green). Varios obreros poseen otras nacionalidades, realizando trabajos similares: herrero (Francesco Starrini, italiano), mecánico (Doufour Bertrain, francés) y albañil (Raymond Pelausis, francés).

Una familia inglesa, Light-Atsbury, residió en el $\mathrm{N}^{\circ} 5$ de Batten Cottages, Federico Light fue inspector de los Talleres entre 1910 y 1930, en el pueblo de La Gallareta y la ciudad de Villa Constitución, lugares donde fijó domicilio ${ }^{3}$. Los Frost vivían en 1922 en el Nº ${ }^{\circ}$, y reemplazaron a Alfred y Annah Gilbert, de 1893-1894. Según una entrevista a su nieta, el maestro Jorge Harding era nacido en Rangún (India) y vivió en el barrio de 1900 a 1921. La familia austriaca Kanjer, residía en Talleres, otro nombre del Barrio Inglés. Otros apellidos ingleses (Spooner, Doorn, Ransdale, McCabe) también pudieron ser rastreados mediante entrevistas, documentos aislados y notas periodísticas, los últimos entre 1910 y 1930.

La población era totalmente extranjera y europea.

Las relaciones de clase en la sociedad en Europa se vieron modificadas por la Revolución Industrial. En Inglaterra, las jerarquías (ranks) en la sociedad industrial tecnificada -distancias entre puestos o cargos- tendían a ser "cortas" (Mikkelsen 1996) ya que se veían como relaciones técnicas (jefe y subordinado, mandar y saber) en grupos diferenciados compartiendo viviendas construidas para ellos (dwellings) y mejorando su calidad de vida.

Residiendo cerca de los Talleres -proximidad habitual en Inglaterra- los obreros formaban grupos (gangs) cuyo jefe (ganger) organizaba la solución a problemas del servicio. Las inspecciones empresariales suponían residencias más o menos prolongadas, por lo general de varios meses y tan frecuentes, que eran casi permanentes. De ellas dependían la puntualidad y la economía de la empresa y las realizaban jefes técnicos supervisores, administrativos y menores (staff teams) siempre dentro del grupo de empleados white collar (Findlay 1891).

Por lo tanto, hay una organización social basada en clases definidas por el trabajo y por la nacionalidad. La conviviencia respondía a un comportamiento preestablecido desde los reglamentos ferroviarios, hasta los mismos límites de la vida privada, con rasgos incluso intrusivos de tipo paternalista por parte de la empresa (Badaloni 2007) a fin de establecer un "modo de vida ferroviario" que debía desarrollarse al compás del trabajo en los Talleres.

\section{La arquitectura como hábitat diseñado}

La arquitectura pensada para ese modo de vida regulado fue construida como un anexo para el trabajo ferroviario. En Inglaterra, la arquitectura ferroviaria respondía al funcionamiento del ferrocarril, y a ese fin se diseñaba, construía y eventualmente se alquilaba a los obreros y empleados, en un acuerdo laboral que "beneficiaba a ambas partes" (Findlay 1891), aunque el diseño era impuesto por la empresa.

Como edificio colectivo, el Morrison Building consistía en dos edificios de planta baja y un piso, con 12 departamentos (flats) cada uno. La palabra building 
remite a un tipo de edificio urbano, con uso específico. Las plantas bajas poseían jardín individual y se accedía a planta alta por dos escaleras comunitarias, cada departamento constaba de dormitorio, cocina y retrete, unidos por un pasillo al que abrían las puertas de las habitaciones y poseían un hogar con chimenea para calefacción.

Las Batten Cottages eran 12 casas unifamiliares, unidas de a pares y de dos plantas, cada una tenía una planta baja con sala, estar, cocina y comedor, ubicándose en planta alta tres habitaciones, a las que se accedía mediante una escalera de madera y todos los locales, tanto de planta baja como las del piso superior estaban calefaccionadas. El baño era interior y se ubicaba arriba, inmediato a la escalera (Cicutti 1997). Tanto el Morrison como el Batten Cottages poseen números correlativos comenzando por el $\mathrm{N}^{\circ} 1$ en la vivienda del extremo sudoeste.

Pueden observarse dos calidades diferentes de construcción. Los ladrillos del Morrison son más salitrosos y blandos, aunque de similar formato (promedio $25 \times 12 \times 5,5 \mathrm{~cm}$ ), sus morteros carecen de cemento y poseen diferente estado de conservación. Las viviendas Batten Cottages poseen ventanas tipo mirador, denominadas square bay (hoy bow-windows) con decoraciones de madera y porche o veranda. El edificio Morrison posee un ornato colectivo simétrico, sin jerarquizar las puertas, mediante decoraciones superiores de madera, denominadas gable endings, de uso tradicional en viviendas ferroviarias inglesas.

Se puede argumentar que hubo una manera de vivir para las Cottages y otra manera para los departamentos del Morrison. Las primeras probablemente se diseñaron para familias y las segundas para hombres solteros o al menos, hombres con familia muy reducida, con una la relación entre habitaciones disponibles de 3 a 1 . Además, las cottages poseían espacios de representación (hall room y living) para recepción u ocio, dormitorios para dos hijos, con dormitorio separado para el matrimonio. Tanto para el conjunto Batten como para el conjunto Morrison, con baños, cocinas individuales, calefacción y jardines, se buscaba una calidad de vida específicamente pensada mediante un hábitat artificial, la arquitectura.

Otra característica del barrio eran los jardines. Históricamente, a finales del siglo XIX (1870-1890) en Inglaterra comenzó la costumbre de dotar a la arquitectura de un pequeño jardín de características en apariencia descuidadas (Scott-James 1981 y Lane 2012).

Incluía plantas ornamentales (flowerplants), enredaderas (embrace plants) y comestibles (herbs), limoneros o naranjos. Este jardín informal "no geométrico" significaba una representación doméstica de la naturaleza "salvaje", un lugar semipúblico intermedio a lo privado, donde se charlaba con el vecino tras las verjas de madera (fences) mientras que la dueña de casa cuidaba de los rosales o cosechaba hierbas para cocinar. Los jardines eran remedo de los originales ingleses, elementos paisajísticos que combinaban "lo bello con lo útil" (Scott-James 1981).

El conjunto poseía también una iglesia-escuela, denominada popularmente "El Campanario" o Escuela de los Talleres. Poseía el mismo lenguaje arquitectónico de los talleres centrales: ladrillos a la vista y pilares con remate piramidal. Según el plano del Ing. Thedy de 1899, la iglesia era una breve construcción en un 
predio cercado posterior a las viviendas. Constaba de una sola nave, con escenario, vivienda del pastor o maestro, baño y cocina. Asambleas y actos cívicos, eran evidenciadas por las revistas populares de la época, como Monos y Monadas o Gestos y Muecas (1909-1911).

Estas construcciones se edificaron en un espacio considerado, para le época, como rural, como consta en los censos. En ese contexto no urbanizado, el barrio estaba delimitado al norte por la actual calle Ferrocarril Central Argentino y al sur por los predios ferroviarios. Se dispusieron pilares de ladrillos sosteniendo un alambrado entre el predio del barrio y las vías del trayecto a Sunchales y de este modo quedaba un espacio verde entre el barrio y el trazado ferroviario, probablemente para fines de ocio o deportes. A dicho predio se accedía por una entrada en Av. Castellanos. Más allá del alambrado, se ubicaron dos contextos de deposición de basuras (MO1 y MO2) y hacia el sur existía una serie de bañados, quizás provocados por los movimientos de tierra ferroviarios.

Históricamente, los barrios rosarinos (como el cercano Refinería) no se cercaron, sino que se fundaron como extensiones de la ciudad, sin límite físico colectivo. La calle, la línea de edificación definían el trazado barrial, sólo el lote individual se alambraba. Para el Barrio Inglés, en cambio, el alambrado implicó una forma de recortar un espacio, diferenciándolo del resto del territorio, incluso con aparejos guardaganados y servicios de agua y luz conectados a los Talleres. Así delimitado, el recorte territorial iba desde la macro división del suelo (barrio), a la intermedia (manzanas, calles y edificios) hasta la micro división en parcelas, unidad mínima de suelo habitable, formando una unidad casi independiente de la ciudad.

Definiendo "asentamiento" como una unidad analítica arqueológica primaria y "patrón de asentamiento" a la forma en que la gente se apropia del entorno en un determinado momento histórico (Chang 1962 y Prieto Rodríguez 2011), se observó cómo el Barrio Inglés se "asienta" en un espacio mediante un patrón de rectas cruzadas, calles, muros, patios y compartimientos, elementos fundamentales de la urbe. El grupo dividió, parceló, subparceló, concentró, cercó y cualificó ordenada y geométricamente- el territorio y se definió así lo público, lo semipúblico y lo privado, desde la calle a la intimidad. Mediante un patrón de calles y muros, se insertó lo urbano "en" lo rural, considerando ese orden (barrio, quarter) como opuesto al "country" (campo) considerado éste disperso y vacío y por lo tanto, diferente y "no civilizado" (Barenboim, 2011). Había entonces un "adentro" y un "afuera" marcados físicamente, separando materialmente el barrio del territorio colindante, autonomizándolo, con un ingreso controlado: una manera de fundar, conservar y diferenciar una forma de vivir, pensándola dentro de la dinámica urbana de fines del siglo XIX.

\section{Un consumo diferenciado para un grupo complejo}

Si aceptamos la idea de un comportamiento basado en la diferencia de los habitantes del Barrio Inglés con otros grupos (británicos, europeos, rosarinos) y 
subgrupos dentro del grupo mayor (ranks o clases, nacionalidades) veremos la complejidad del "Barrio Inglés" desde lo colectivo, que se reflejó en el registro arqueológico como "consumos específicos".

En dicho consumo, ciertas características visibles "hacia fuera" (el ladrillo de las casas, los jardines) se articulaban con otras visibles "hacia adentro" (uso de cierta cerámica o consumo de cierta comida) como diferenciación interna.

Lo importante, puede pensarse, era mantener una doble diferencia, externa e interna, mediante constantes operaciones identitarias compartidas. Esto se realizó con los elementos disponibles, a veces distintos a los de la metrópoli, a veces iguales, porque los recursos con frecuencia eran los originales ingleses, obtenidos por la importación, como cerámicas de calidad, salsas, dentífricos, agua mineral, juguetes, etcétera. Pero otros recursos eran diferentes a los disponibles en Inglaterra, aunque necesarios, como los materiales para la comida.

Si se observa el registro arqueológico de los basurales inmediatos (MO1, MO2 y MO3) puede verse que existen, por un lado, fragmentos comunes a otros contextos de deposición (por ejemplo, JU 1 a 5 o MD1): loza blanca lisa, CeresWheat, botellas de vino hechas a molde y huesos de vacuno y ovino ${ }^{4}$. Pero se hallaron elementos particularizados que no fueron hallados en sitios vecinos: fragmentos de porcelana europea en cantidad, de frascos de medicamentos y de botellas de agua mineral y salsa Worcestershire, fragmentos de un plato de juguete y un fragmento de botella de químico fotográfico (Figura 2).

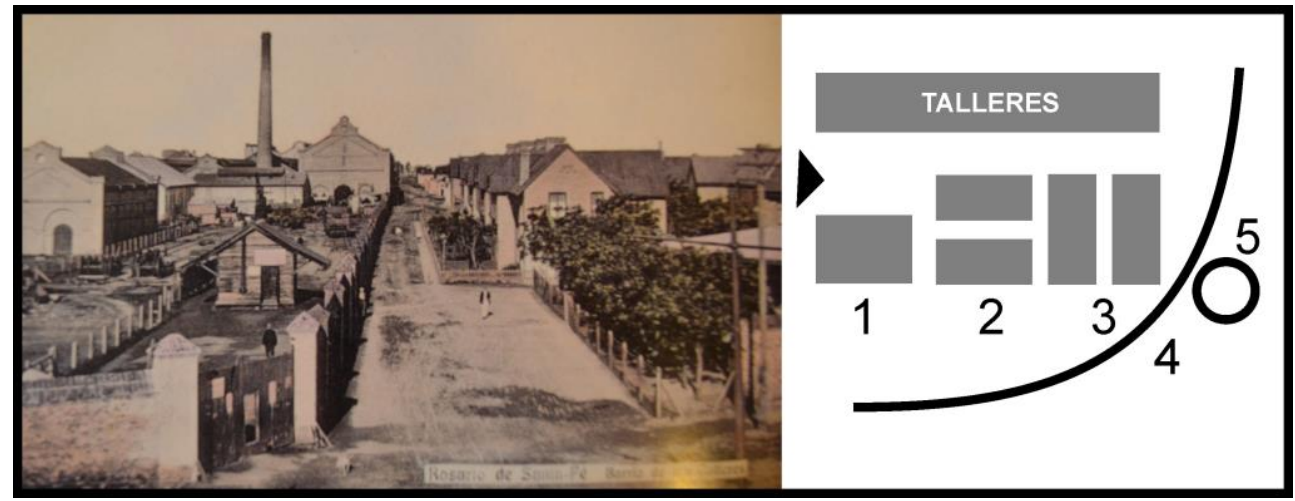

Figura 2: Fragmentos de: 1- Platos de juguete, porcelana europea. 2- Loza decorada por transferencia y sobre relieve "embossed"; 3- Porcelana china, 4Plato "Ironstone china", 5- Botella fixer fotográfico Widmayer, 1906. 6- Botella ginebra "Wiedemburg" c. 1900. Recolección superficial sitio MO1. Registro RENYCOA 2014. Gentileza Lic. Soccorso Volpe.

Estos consumos -reflejados indirectamente por el registro arqueológicoimplicaban, como se dijo, diferencias. Mientras que las diferencias internas son en función de la hierarchy -la jerarquía de clase -que se refleja en la arquitectura- la unificación se da en función de lo común, de lo que es étnicamente esencial y una 
de esas esencias es, justamente, la calidad manifestada en la particularidad y tipo de consumo.

De este modo, lo cualitativo (lo jerárquico y la diferencia) une y separa, cualifica y divide, manda y obedece, en un juego de representatividades adaptativas, constituyendo un grupo en situación de contacto con la sociedad de una ciudad fuertemente europeizada, por su historia (Rigotti y Pampinella, Baremboim 2008, Ciavazza y Dosztal 2016)

No hay un trasplante, sino una adaptación "étnica"5 a un contexto extraño al original y debió ser obligada pero no idéntica a la ocurrida en India o Egipto. Debió tener en cuenta factores distintos. En el marco socioeconómico argentino de capitalismo dependiente, no era casual que además de sus consumos diferentes, la "colectividad" (como se denominaba a las avocaciones mutuales de inmigrantes) británica tuviese dispositivos étnicos ${ }^{6}$ de adaptación y sociabilidad como templos, un cementerio, escuelas, visitas de predicadores evangelistas, embajadores y cónsules, y hasta un barrio completo para jefes, Fisher Town. O sea, se construyeron dispositivos de diseño específicamente grupal.

Los inmigrantes británicos del "Barrio Inglés" debieron a la vez diferenciarse e integrarse, sin que esto último signifique una argentinización. Así, podría suponerse que la condición británica era monárquica, clasista y multiétnica (social ranks, ingleses, irlandeses, escoceses), condición a conservar dentro de las posibilidades socioeconómicas del territorio, manteniendo la "calidad de persona" y la especificidad de los individuos. Así, los mejores materiales y la vida familiar en una propiedad "privada" se contrapone a otra colectiva en viviendas de peor materialidad, una oposición de "vivir al lado de" respecto a "encima de" o "abajo de", que significaban -en última instancia- "peor" o "mejor" persona, familia o grupo, propios de una sociedad hegemónica y organizada con esos parámetros clasistas propios de las monarquías imperiales (Furbank 2005).

\section{¿Qué era el Barrio Inglés?}

En la arqueología histórica y urbana, hoy son frecuentes dos posturas epistemológicas. Una adopta una postura descriptiva del registro arqueológico y promueve aspectos informativos sobre una cultura cuyos vestigios se estudian. En otros trabajos se puede ver la creación de modelos inductivos, extendiendo leyes internas del registro a otros vestigios de los mismos grupos. Procediendo ontológicamente, nos conformamos con obtener una definición del Barrio Inglés que nos aproxime al máximo a la que le dieron los habitantes originales. Para ello, preferimos una perspectiva arqueológica integral y comparativa, articulando todas las manifestaciones del pasado (incluyendo la memoria de su pasado) y observando las lógicas internas de esos fragmentos (Prieto Rodríguez 2011).

Así, el "Barrio Ingles" lejos de ser un enclave (un territorio institucionalizado y soberano) o un gueto (por lo general forzoso) se trató de la materialización de una lógica de "relaciones pareadas", tanto internas (al lado / arriba; arriba / abajo; clase media / clase proletaria; familia / individuo; consumos particulares / con- 
sumos generalizados) como externas (lo británico / lo local; inglés/ no inglés; lo nuestro / lo ajeno). Por otro lado, podemos argumentar que existió el concepto de "particular calidad de persona" (Ashton y Young 1977; Mikkelsen 1996, Furbank 2005) dentro de un grupo con una hierarchy interna, que se dota a sí mismo de una correspondiente "particular calidad material" (mejor/peor)

Emplazados en el territorio, pensamos que esos pares se resolvieron materialmente en una serie, ordenada jerárquicamente de oeste a este: 1- Iglesia y escuela (maestro, pastor) 2- Casa (white collar employees) 3- Edificio (workers), 4- Tendido ferroviario y alambrado (límite) y 5 - Basural (afuera del barrio), cada uno con sus materialidades (Figura 3).

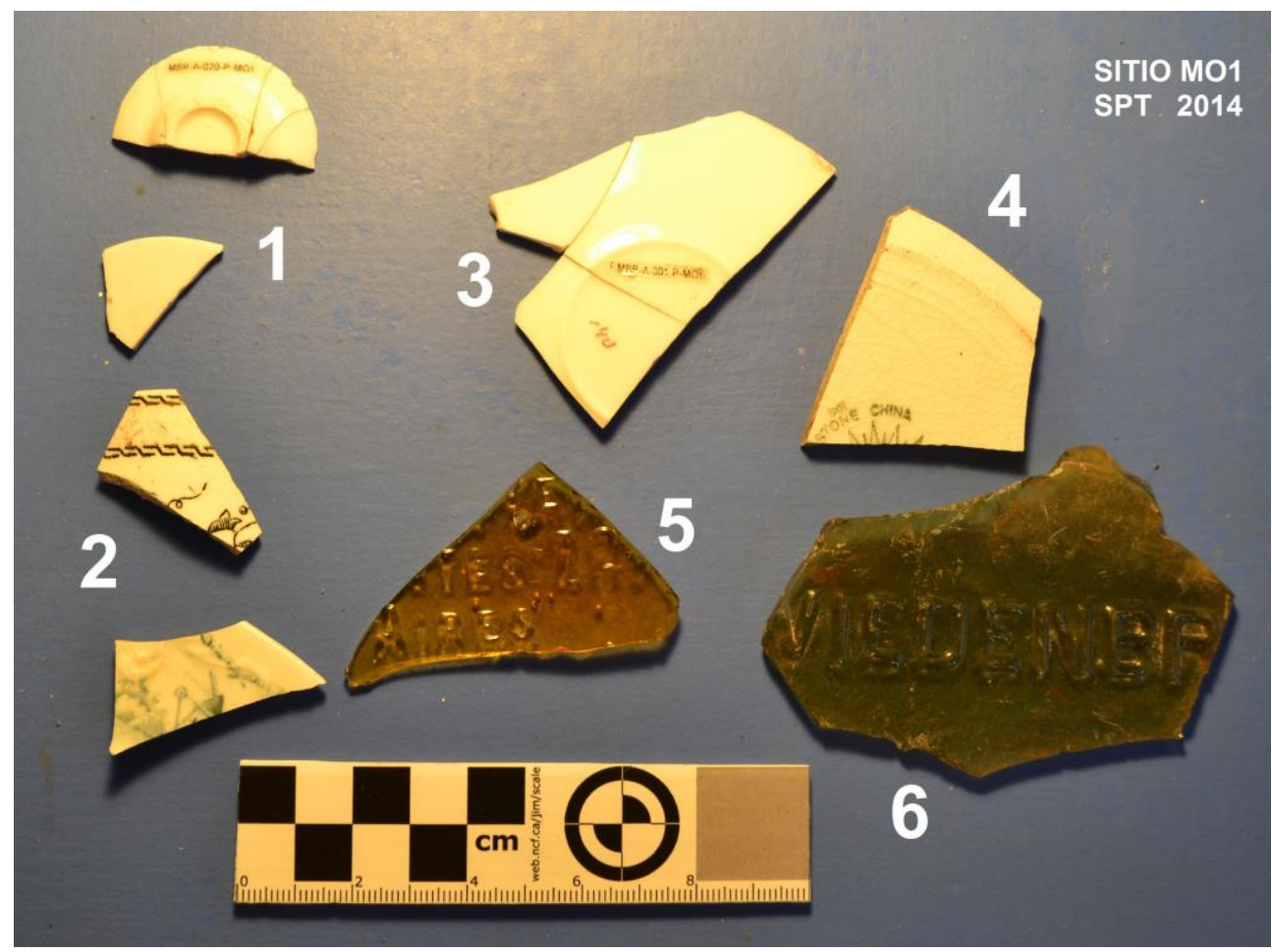

Figura 3: Vista del "Barrio Inglés” y planta esquemática con la serie jerárquica propuesta. Colección Museo Itinerante del Barrio de la Refinería.

Creemos que este orden material no fue casual ni cronológico, sino una intención específica de diseño del barrio como hábitat artificial, una manera de convivir ordenada por calidades, según las pautas del grupo que lo construyó y que lo habitó. Esto se reflejó en el registro arqueológico, dentro de un territorio que no es un simple "telón de fondo de lo cotidiano" (Piazzini Suárez 2006) sino que es un contexto diseñado, que al ser leído como extraño y a la vez propio, sustenta y da sentido al barrio. ¿No es lo que estaba ocurriendo, en 1890, en el Imperio Británico y las poblaciones locales "propias y a la vez extrañas" al relacionarse éstas con la "inserción" inglesa? 
El Barrio Inglés, lejos de ser la habitual expresión estereotipada de las guías de turismo, fue una adaptación a condiciones socioeconómicas diferentes a las de la metrópoli, reproduciendo la hegemonía de un grupo monárquico y clasista (ingleses) sobre otro (obreros ingleses y no ingleses) y separado de un tercero (rosarinos locales e inmigrantes),

Por lo tanto, se podría argumentar que el Barrio Inglés -ontológicamente hablando- fue una autorepresentación local de la sociedad británica, mediante la construcción colectiva de un "esencialismo situacional" basado en la calidad de las personas como orden social y confrontando ese orden a la emergente realidad rosarina.

\section{Consideraciones finales}

La mirada folk o patrimonialista, en base a lo inmediato y evidente, nunca podría penetrar la opacidad de estos grupos en su contexto (un grupo europeo en un Rosario inmigratorio, a su vez inmerso en un sistema imperialista). La "esencia" no es lo que el arquitecto, el museólogo o el guía de turismo pueden ver hoy (una "esencia de ladrillos a la vista") sino que esa "esencia" es lo que el propio grupo pensó de sí mismo en cierta situación, como conjunto de elementos "esenciales" imposibles de perder o trasformar, sin riesgo de cambiar en todo o en parte la propia identidad de origen.

"Lo inglés" no es lo material-observable-hoy: fue la idea que tuvieron "los ingleses" de sí mismos, al construir el barrio y vivir en él. Esto sería inaccesible sin integrar al análisis todos los elementos disponibles, articulados en una cultura y una historia, de la que sólo han perdurado relictos de los cuales sólo el más visible fue la arquitectura. Ésta no se diferenciaría epistémicamente de otros consumos, como la vajilla, la vestimenta o las comidas. Tomados aisladamente, todos los fragmentos pueden ser considerados "recortes de realidad" observados hoy por el investigador y encuadrados a nivel de categoría de análisis o taxones.

En cambio, al integrarlos en un todo material, podrían pensarse como "intermediarios" entre una condición de vida pasada y otra actual, fragmentos que coexistieron dinámica y simultáneamente y factibles de articular en un contexto arqueológico.

Operativamente y a futuro, puede pensarse una arqueología urbana que considere arquitectura y el basural, el documento y la memoria como una serie articulada, un "continuo heterogéneo" cuyo análisis permitiría acceder a las relaciones dentro de un contexto arqueológico complejo y reticular. Un contexto vasto, que abarca y excede el sitio arqueológico "Barrio Inglés" pero que le da sentido, ya que, para los actores originales, "la realidad pasada fue una sola".

En ese marco se puede pensar necesaria (y hasta inevitable) una definición del objeto de estudio, una ontología de esa realidad pasada lo más cercana a la "idea" que los pobladores tuvieron sobre su realidad, a la que el investigador debe aproximarse asintóticamente: campos colectivos históricos ya invisibles, que se 
delimitaron, relacionaron, interpenetraron, dibujaron y desdibujaron y de los cuales sólo quedan fragmentos.

Un análisis arqueológico integrado y comparativo de esa realidad compleja puede volver visibles esas dinámicas, sus causas, lógicas y sentidos, a fin de esclarecer paulatinamente un pasado que, hasta ahora, permaneciera opaco a los rosarinos.

\section{Agradecimientos}

A los vecinos del Barrio Inglés, Lic. Soccorso Volpe, Lic. Soledad Biasatti, Cecilia Arias Morales. A Edgardo Platanía y Ángela Tasca del Museo del Barrio Refinería.

\section{Notas}

1- Dada la necesidad de radicación el personal, El Barrio Inglés rosarino, a pesar de su singularidad, no es único, verificándose unidades parecidas en Bahía Blanca, Campana, Junín y barrios porteños como Caballito, Lomas de Zamora, Temperley y en otros países, sobre todo Australia.

2- Censo Nacional de 1895, Rosario, Sección 14, pags. 36 a 40.

3- Archivo Light-Atsbury del Museo Itinerante del Barrio de la Refinería, catalogado por Cecilia Arias y Soledad Biasatti en 2014.

4- MO se corresponde a basurales inmediatos al Morrison Building, MD refiere a varios basurales ubicados en una depresión denominada "Laguna de Mandinga" y JU a calle Junín.

5- Definimos como etnia a un grupo nacional con identidad propia, en el sentido genérico europeo y no con el que se le da habitualmente en Latinoamérica o sea no-blanco (Hoffmeyer-Zlotnik y Warner, 107).

6- Para este trabajo, se consideró el concepto "dispositivo" como una herramienta colectiva, emergente, para la aplicación en la realidad emergente o situacional de un grupo. Por ejemplo, las postales a las que se pudo acceder mostraban una blanca, probablemente la bandera de Inglaterra con la cruz de San Andrés y otra verde, con el "Arpa de Oro" que representaba a Irlanda bajo dominio británico. Esto permitió inferir una "hegemonía inglesa" por sobre los otros grupos étnicos residentes en el Barrio Inglés (escoceses, irlandeses, galeses, italianos, franceses y austriacos), en un contexto inmigratorio - demográfico sumamente dinámico.

\section{Referencias bibliográficas}

ARDELEAN, C. F. 2004. Factores causales del patrón de asentamiento en arqueología. En: Boletín De Antropología Americana No 40-Enero-Diciembre.

ASHTON, E.T. y YOUNG, A.F. 1977. British Social Work in the Nineteenth Century. 4ta. ed. Routledge and Kegan Paul Lld. Londres. 
BADALONI, L. I. 2007. Prácticas empresariales paternalistas, sus alcances y límites en el disciplinamiento y control de la mano de obra. El caso del Ferrocarril Central Argentino durante las primeras décadas del siglo XX en Rosario y alrededores. Buenos Aires. págs. 507-526

BARENBOIM, C.A. 2011. Estructuración, crecimiento y transformación urbana en la ciudad de Rosario. En: Proyección 10. Vol. 5. Enero-febrero 2011. Planificación territorial: presencias y ausencias. Pp. 124-141

CICUTTI, B. 1997. Viviendas Empleados Ferrocarril Central Argentino. En: Conocer y Cuidar la ciudad en que Vivimos. Sector Norte. Municipalidad de Rosario. UNR. Rosario. Pp. 30-33.

DAMUS, S. 2013. Al sesquicentenario del Ferrocarril Central Argentino. ARAR. Ed. Rosario.

DENAULT, L. y J. Landis. 1999. Motion and Means: Mapping Opposition to Railways in Victorian Britain." History 256. Mount Hol1891yoke College. Londres.

CUHIAVAZZA, D. y DOSZTAL, I. 2016. Inmigrantes en el chaco austral santafesino: estudios arqueológicos históricos en la casa de la administración de Alexandra Colony, Santa Fe, Argentina. En: Revista Latino-Americana de Arqueología Histórica | Vol. 10 | No. 2 |Jul - Dez | 2016. Pp. 46-71.

FINDLAY, G. 1891.The working and management of an english railway. Whittaker \& Co. Londres. Pp. 68-72.

FURBANK, P.I. 2005. Un Placer Inconfesable o la Idea de Clase Social. Paidos. Buenso Aires.

HOFFMEYER-ZLOTNIK, J. Y WARNER, U. 2010. The Concept of Ethnicity and its operationalisation in Cross-National Social Surveys. En: Metodološki zvezki, Vol. 7, No. 2, 2010, 107-132.

LANCIOTTI, S. 2007. Inversión británica y redes empresariales: La estructura organizativa y las estrategias de gestión del grupo Morrison en Argentina, 1881-1962. En: X Congreso Internacional de la AEHE. 8, 9 y 10 de septiembre 2011. Universidad Pablo de Olavide. Carmona (Sevilla).

LANE, C. 2012. An introduction to cottage gardening. En: The Cottage Garden Society Magazine. Marzo, N25. Cottage Garden Society Editions. Londres. Pp. $11-15$. 
MARTÍNEZ DE SAN VICENTE, I. 1985. La formación de la estructura colectiva de la ciudad de Rosario. En: Cuadernos del Centro Universitario Rosario de Investigaciones Urbanas y Regionales, II, 7, Rosario: Editorial UNR. Rosario. Pp. 1-64.

MIKKELSEN, F. 1996. Working-class formation in Europe: in search of a synthesis. International Institute of Social History. Ámsterdam. Pp. 5-41.

PIAZZINI SUÁREZ, C. 2006. Arqueología, espacio, tiempo: una mirada desde Latinoamérica. En: Arqueología sudamericana. Vol. 2, Nº1, enero. Universidad Nacional de Catamarca.

PRIETO RODRÍGUEZ, M. 2011. Los patrones de asentamiento. Una herramienta metodológica para la reconstrucción del pasado. En: Boletín Antropológico. Año 29, No 82, Julio-Diciembre, 2011. Universidad de Los Andes. Mérida, Venezuela. Pp. 116-131.

RIGOTTI, A. M. Y PAMPINELA, S. 2008. Historia Urbana: De Poblado Espontáneo a Ciudad de Contrastes. En: Gonzalez Montaner, B. (coord.). Guías de Arquitectura Latinoamericana: Rosario, Arte Gráfico Editorial, Buenos Aires. Pp. 6-18.

SCOTT-JAMES, A. 1981. The Cottage Garden. Allen Lane. Londres. Pp. 22-32.

Recibido: 10 de abril 2016.

Aceptado: 20 de septiembre 2016. 